\title{
EXPERIÊNCIA ESTÉTICA NA FORMAÇÃO CONTINUADA DE PROFESSORES NA ESCOLA
}

\author{
AN ESTHETIC EXPERIENCE IN CONTINUING \\ TEACHER TRAINING IN SCHOOL \\ EXPERIENCIA ESTÉTICA EN LA FORMACIÓN CONTINUADA \\ DEL PROFESORADO EN LA ESCUELA
}

\author{
Rosy GonÇALVES ${ }^{1}$ \\ Laura Noemi ChaluH ${ }^{\mathrm{I}}$ \\ ${ }^{\mathrm{I}}$ Universidade Estadual Paulista (UNESP), Rio Claro/SP - Brasil
}

RESUMo O presente trabalho é um recorte de pesquisa de mestrado que teve como objetivo geral analisar os processos formativos desencadeados no contexto das Horas de Trabalho Pedagógico Coletivo (HTPCs) e que tinham como pauta as experiências estéticas. Neste trabalho discutimos a formação de professores no contexto escolar envolvendo a linguagem literária, a linguagem cinematográfica e a linguagem visual, propulsoras de experiências estéticas. Socializamos as inquietações e práticas promovidas por uma professora coordenadora iniciante preocupada com a formação continuada dos professores no contexto de uma escola municipal de Educação Infantil e Ensino Fundamental do município de Rio Claro/SP. Trata-se de pesquisa narrativa (LIMA; GERALDI; GERALDI, 2015) que tomou como objeto de estudo as práticas de formação continuada instituídas pela referida professora coordenadora. Para compor este trabalho utilizamos as escritas do diário de bordo pessoal da professora coordenadora; registros dos professores e equipe gestora contidos na Pasta de Memórias das HTPCs e fichas avaliativas das HTPCs. Para desenvolver o processo de interpretação dos dados nos inspiramos no paradigma indiciário. A pesquisa desvelou que a experiência estética favoreceu uma proposta formativa humanizadora e implicou na ressignificação da própria atuação da professora coordenadora.

Palavras-chave: Professora Coordenadora; Formação Continuada; ExperiênCia EsTÉTICA.

ABSTRACT The present work is an excerpt from a master's research that had as its general objective to analyze the training processes triggered in the context of the Collective Pedagogical Work Hours (HTPCs) and that had as a guide the aesthetic experiences. In 
this work we discuss the formation of teachers in the school context involving the literary language, the cinematographic language and the visual language, propellers of aesthetic experiences. We socialize the concerns and practices promoted by a beginning coordinating teacher concerned with the continuing education of teachers in the context of a municipal school for Early Childhood and Elementary Education in the city of Rio Claro/SP. It is narrative research (LIMA; GERALDI; GERALDI, 2015) that took as an object of study the practices of continuing education instituted by the referred coordinating teacher. To compose this work, we used the writings of the personal logbook of the coordinating teacher; records of teachers and management staff contained in the HTPCs Memories Folder and HTPCs assessment sheets. To develop the process of interpreting the data, we took inspiration from the evidential paradigm. The research revealed that the aesthetic experience favored a humanizing formative proposal and implied in the formation a new meaning of the coordinator professor's own performance.

Keywords: Coordinating Teacher; Continuing Education; Aesthetic Experience.

RESUMEN El presente trabajo es un recorte de una investigación de Maestría que tuvo como objetivo general analizar los procesos formativos desarrollados en el contexto de las Horas de Trabajo Pedagógico Colectivo (HTPCs) y que tenían como pauta las experiencias estéticas. En este trabajo discutimos la formación de profesores en el contexto escolar que contempla el lenguaje literario, el lenguaje cinematográfico y el lenguaje visual, propulsores de experiencias estéticas. Socializamos las inquietudes y las prácticas promovidas por una profesora coordinadora iniciante preocupada con la formación continua de los profesores en el contexto de una escuela municipal de Educación Infantil del municipio de Rio Claro/SP. Se trata de una investigación narrativa (LIMA; GERALDI; GERALDI, 2015) que tomó como objeto de estudio las prácticas de formación continua instituidas por la referida profesora coordinadora. Para componer este trabajo utilizamos los escritos del diario de a bordo personal de la profesora coordinadora; registros de los profesores y del equipo de gestión incluidos en la Carpeta de Memorias de las HTPCs y las fichas de evaluación de las HTPCs. Para desarrollar el proceso de interpretación de los datos nos inspiramos en el paradigma indiciario. La investigación reveló que la experiencia estética favoreció una propuesta formativa humanizada e implicó la resignificación de la propia actuación de la profesora coordinadora.

Palabras clave: Profesora Coordinadora; Formación Continuada; Experiencia EsTÉTICA.

\section{INTRODUÇÃo}

O presente trabalho é um recorte de uma pesquisa (GONÇALVES, 2020) que teve como objetivo geral analisar os processos formativos desencadeados no contexto das Horas de Trabalho Pedagógico Coletivo (HTPCs) e que tinham como pauta as experiências estéticas na busca por fomentar a valoração e a participação dos professores neste espaço formativo na escola. Problematizamos aqui as práticas de formação instituídas nas HTPCs pela primeira autora deste artigo, professora coordenadora iniciante de uma escola pública 
que atende as etapas da Educação Infantil e Anos Iniciais do Ensino Fundamental no município de Rio Claro/SP.

A HTPC é um espaço privilegiado de formação na escola, representando historicamente uma conquista dos profissionais da Educação. Isto, por propiciar uma formação em contexto que considera os saberes da experiência docente como constituintes do processo formativo (CHALUH, 2008). Este espaço potencializa o processo formativo atendendo as especificidades dos docentes de cada unidade educacional, considerando a singularidade de cada contexto educativo. As HTPCs, no referido município, estão compostas por duas horas aulas semanais e dele participam professores PEB I (Professores da Educação Básica I que atuam nos Anos Iniciais do Ensino Fundamental) e PEB II (Professor da Educação Básica II que atuam nos Anos Finais do Ensino Fundamental e Ensino Médio).

Acerca da formação continuada, destacamos algumas considerações de Chaluh (2008) que afirma a necessidade de:

[...] pensar no resgate da experiência das professoras como instância fundamental para refletir/construir saberes; a considerar os professores como construtores/gestores da escola; a valorizar como modelo de formação a constituição de grupos de trabalho, e considerar a importância do saber pedagógico para a prática docente [...] (CHALUH, 2008, p. 76).

Partindo da concepção de que somos sujeitos inacabados (FREIRE, 1996), afirmamos a importância de legitimar uma prática formativa na qual os profissionais compreendam o sentido do seu fazer-pensar docente da sua prática cotidiana, numa perspectiva reflexiva. Nesse sentido, apresentamos a singularidade das práticas instituídas pela referida professora coordenadora e que foram propostas na tentativa de viabilizar uma formação continuada humana e reflexiva.

No entanto, um dos conflitos vividos pela professora coordenadora foi perceber a desvalorização desse espaço formativo, a HTPC, até mesmo pelos próprios docentes. Assim, cabe ressignificarmos ações para a compreensão e valorização desse espaço formativo na escola explicitando sua potencialidade no processo de constituição docente.

A primeira autora do trabalho que, como já referido, é professora coordenadora iniciante viveu um outro conflito: como instigar a participação dos professores em um processo formativo que contemplasse e legitimasse a reflexão de questões teórico-práticas, que fossem envolventes e significativas para os professores, instigando-os ao diálogo e ao posicionamento crítico frente o que estava sendo proposto como discussão?

Dessa forma, ao observar que a formação continuada proposta nos HTPCs, centrava-se mais no fazer da professora coordenadora e não provocava os outros a uma reflexão e participação comprometida com a própria formação, ao longo do ano de 2018, a professora coordenadora inquieta com o pouco envolvimento e valoração dos professores no processo formativo ocorridos nos espaços de HTPC, foi se arriscando a um fazer diferenciado, à uma prática formativa a partir da qual buscou repertoriar (numa perspectiva teórico-prática) a si própria e aos professores promovendo práticas que contemplassem nesse processo diferentes linguagens.

Entendemos a linguagem a partir da concepção de Bakhtin (1999) enquanto enunciação, interação. A linguagem (nas suas diferentes expressões) é por constituição dialógica, 
linguagem como produção de sentido. Linguagem enquanto fenômeno heterogêneo, polifônico, linguagem concebida enquanto $\operatorname{signo}^{1}$ e por isso com marcas ideológicas.

Assim, os conflitos vividos pela professora coordenadora promoveram uma mudança na composição e organização das pautas definidas para os HTPC ao propor práticas formativas que articulasse a linguagem literária, cinematográfica e visual.

Assim, o trabalho pedagógico desenvolvido pela professora coordenadora ao longo desse ano foi tomado como objeto de estudo na pesquisa de mestrado, intitulada "Experiências estéticas na formação de professores na escola: mediação da professora coordenadora" (GONÇALVES, 2020) e foi sistematizado numa investigação na perspectiva narrativa (LIMA; GERALDI; GERALDI, 2015) que considera as experiências do vivido como uma abordagem de pesquisa, perspectiva que legitima a produção de conhecimento a partir do cotidiano vivido na escola, dialogando com ela e a partir dela. Observando com atenção os pequenos detalhes inseridos em comentários e gestos, assim como nos materiais produzidos, a professora coordenadora e pesquisadora, inspirada pelo paradigma indiciário (GINZBURG, 1989), procurou nos dados marginais, indícios que sinalizassem aspectos relacionados com as propostas formativas singulares que ela se propôs a desenvolver nas HTPCs. E assim, poder compreender as implicações que suas práticas formativas, entrelaçadas pelas linguagens, tiveram na formação dos docentes e equipe de gestão.

Os professores participantes da pesquisa se constituíram em 12 professores, sendo 10 professores PEB I e dois professores PEB II. A escola conta ao todo com aproximadamente 65 alunos da Educação Infantil e 82 alunos do Ensino Fundamental, totalizando 147 alunos.

Neste trabalho dialogamos com alguns teóricos que deram sustentação para pensar na concepção de experiência estética e compartilhamos uma proposta de formação continuada que provocou a sensibilização dos professores da escola ao entrar em contato com diferentes linguagens.

Para a realização do trabalho, trazemos as escritas referentes ao diário de bordo pessoal da professora coordenadora, onde relatava sua perspectiva sobre os encontros formativos e alguns dos relatos contidos na Pasta de Memórias das HTPCs, onde os professores e equipe gestora foram convidados a registrar suas impressões e memórias sobre a formação vivenciada após as HTPCs. Tais registros não tinham nenhum formato específico, nem tampouco foi solicitado um registro em forma de ata do encontro, mas sim, uma escrita que abarcasse a perspectiva singular sobre cada encontro. Além desses registros, também socializamos as fichas avaliativas, as quais contém a avaliação dos professores em relação aos encontros formativos em HTPCs, avaliando esse momento com sugestões e apontamentos.

\section{EXPERIÊNCIA ESTÉTICA: ALGUMAS COMPREENSÕES}

As inquietações da professora coordenadora sobre as possibilidades de potencializar os processos formativos desenvolvidos por ela na escola e que estimulassem o diálogo e

\footnotetext{
Signos: objetos naturais, produtos naturais, tecnológicos ou de consumo que podem se tornar signos e adquirir um sentido que ultrapasse suas próprias particularidades. Compreender um signo consiste em aproximar o signo apreendido de outros signos já conhecidos. A compreensão é uma resposta a um signo por meio de outro signo, produzindo uma cadeia de compreensões.
} 
o posicionamento dos envolvidos frente à formação proposta, a levaram na busca de caminhos ainda não percorridos por ela anteriormente, mas pelos quais ela queria transitar já que intuía que não apenas questões teórico-práticas poderiam dar subsídios a uma formação ampla, humana. Concordamos com Catani (2006) quando a autora afirma que nos processos de formação de futuros professores não apenas temos que valorizar questões científicas ou didático-pedagógicos. A autora afirma a necessidade de darmos a atenção que merecem os "sentimentos e relações que os sujeitos constroem para sua inserção na realidade" (CATANI, 2006, p. 83). Entendemos que as considerações da autora precisam ser consideradas no contexto de formação continuada de professores em exercício.

Assim, a professora coordenadora, a partir de sua própria experiência de ter participado de cursos de extensão na universidade, Universidade Estadual Paulista (UNESP, campus Rio Claro) e, nos quais conseguiu ampliar seu olhar e compreensão para a potencialidade das linguagens no processo formativo, justamente por possibilitarem vivências de experiências estéticas, ela decidiu se arriscar, decidiu apostar em outras formas de promover suas práticas formativas. Nesse sentido, compôs as HTPCs com práticas permeadas por diferentes linguagens, as quais envolveram os participantes, podendo despertar sensações e sentimentos. Assim, envolvida com a proposição de ampliar o entendimento de uma formação atenta às experiências estéticas, foi necessário compreender as diferentes concepções de experiências estéticas que circulam no meio acadêmico e, com isto, foi possível dialogar com as produções de Loponte (2017), Gadamer (2010), Duarte Jr. (1991), Soto e Vasta (2016) e Santos (2003).

É necessário destacar que existem muitas pesquisas educacionais que abordam a formação continuada, e neste cenário, observa-se que há algumas produções voltadas para a temática das experiências estéticas na formação de professores. Entretanto, inúmeros são os sentidos creditados para a palavra estética nessas produções, criando assim algumas limitações e confusões (LOPONTE, 2017).

Conforme Loponte (2017), a palavra estética, ao longo do tempo, vinculou-se a diferentes contextos, renovou-se, porém, a sua indeterminação e a complexa relação com o sensível foram asseguradas.

\footnotetext{
A palavra estética remete igualmente, na linguagem comum, a um corpus filosófico, a uma historicização da arte, a métodos e objetos relacionados com o estudo do sensível, remete a uma teoria sobre o belo e a produção de uma disciplina que aparece como tal em 1750 com o trabalho a que Baumgarten batizara com esse nome [...]. (FRIGÉRIO, 2007 apud LOPONTE, 2017, p. 431).
}

Nessa perspectiva sensível de perceber o mundo, Gadamer (2010, p. 07) corrobora para as experiências estéticas como encantamento, "a ação de se sentir tocado por algo de uma tal forma que esse algo provoca não apenas perturbação, confusão, perplexidade, mas também admiração, comoção, consternação". Sendo assim, Gadamer evidencia as potencialidades das experiências artísticas como forma de envolver o sujeito de maneira que ele se sinta tocado por elas, já que essas experiências não se limitam somente aos sentidos do inteligível, mas também perpassam as faculdades sensoriais, emocionais e intelectuais. 
Portanto as experiências transcendem a concepção da estética que vai muito além do belo, permeando as experiências do sensível, ressignificando o interior e o entendimento de mundo. De acordo com Duarte Jr. (1991)

É possível perceber-se que, em essência, o que ocorre numa experiência estética é que nossos sentimentos são tocados, são despertados pelas formas do objeto e então vibram, dando-se a conhecer a nós mesmos. Como frente a um espelho, onde apreendemos nossa imagem e desvendamos a aparência de nosso corpo, face ao objeto estético descobrimos aspectos de nossa vida interior, vindo a conhecer melhor os nossos sentimentos. Ao revelar-nos o mundo - por meio de seu próprio mundo - o artista nos mostra a nós mesmos (DUARTE JR.,1991, p. 52-53).

Trazemos ainda a perspectiva de Soto e Vasta (2016), segundo as autoras, a experiência estética se refere aquilo que cada indivíduo processa individualmente, diante de algo que o comove, afeta e o toca:

La experiencia estética se refiere al proceso individual a través del cual se percebe, se aprecia, se contempla, se crea, se participa de actos que conmueven, en tanto resultan para el sujeto particularmente impactantes. Son actos de percepción y de producción/generación en los sujetos participan según sus posibilidades individuales y sociales, así como también según sus historias de vida. Cada sujeto, mediado por el tempo y sus experiencias vitales, se conmoverá o no y se contactará o no con diferentes hechos del mundo exterior (SOTO; VASTA, 2016, p. 36).

Embora a palavra estética se mostre muito abrangente em diversos campos semânticos e em diferentes concepções, nas produções estudadas, a experiência estética está vinculada ao campo do saber filosófico, ou seja, compreendida sua intrínseca relação com a arte e o impacto sobre o sujeito. De acordo com Santos (2003):

Muitas coisas chamamos de arte, mas, sobretudo aquilo que se produz como música, literatura, o que se mostra cenicamente e o que nos vem através de outros meios visuais. Já o belo, que de fato pode ser referido às obras de arte, também o pode para uma rosa no jardim ou para um pôr-do-sol laureando o fim do dia (SANTOS, 2003, p. 18).

Diante das várias percepções a respeito da concepção de experiência estética, é possível compreender que elas se relacionam ao sensível e reconhecem a profundidade e o impacto dessa experiência nos sujeitos. Na busca pela compreensão do sentido das experiências estéticas e suas implicações no processo formativo nas HTPCs, a professora coordenadora se indagava constantemente: a experiência estética poderia ser provocada apenas dialogando com o grupo acerca de referenciais teóricos? E qual a necessidade de a experiência estética ser provocada no processo formativo? Diante de tais indagações, a professora coordenadora compreendia que precisava instigar os diálogos através da sensibilização, aproximando os professores de proposições outras, as quais poderiam possibilitar a vivência de experiências estéticas. 
Portanto esse trabalho reconhece a experiência estética em sua amplitude de concepções, destacando sua capacidade de abarcar o estímulo de todos os sentidos quando vivenciada pelo sujeito, provocando além do sensível, os sentidos intelectuais, emocionais, afetivos e sensoriais.

\section{EXPERIÊNCIAS ESTÉTICAS ENTRELAÇADAS ÀS DIFERENTES LINGUAGENS NO CONTEXTO DE FORMAÇÃO CONTINUADA}

Envolvida com as possibilidades de potencializar as HTPCs desvinculando de concepções formativas arraigadas, as quais envolviam ações bancárias que focavam em depositar textos teóricos, a professora coordenadora se propôs a repensar suas práticas formativas e reformular encaminhamentos e propostas relacionadas com a formação dos professores nas HTPCs. Dessa forma, como já referido, buscou articular formações que impossibilitassem qualquer tipo de distanciamento, assim trouxe proposições permeadas pelas experiências estéticas, as quais provocaram sensações, sentimentos, sentidos intelectuais e promoveram o encontro de diferentes percepções.

Diante das inquietações da professora coordenadora ao almejar o engajamento nas HTPCs, percebia que seria insuficiente os professores apenas estarem presentes no momento formativo, objetivava-se o envolvimento de todos nas propostas pensadas e construídas para eles naquele momento, realizando um movimento de leitura da realidade circundante, estabelecendo espaços de interlocução para o acolhimento dos diferentes pontos de vista. Perissé (2009) colabora com nosso entendimento sobre uma formação que possibilite o encontro:

\footnotetext{
Não basta estar no meio da multidão para pertencer a uma comunidade. Não basta estar dentro de uma sala de aula para pertencer a um grupo que se uniu em busca de conhecimento. Encontro significa "entrelaçamento", intercâmbio de possibilidades. Não basta escrever uma palavra ao lado da outra para compor um texto. Não basta posicionar várias pessoas dentro de um palco para que nasça uma apresentação teatral. Em todos esses exemplos, o encontro exige uma relação reversível (PERISSÉ, 2009, p. 85).
}

Intencionava através das linguagens literária, cinematográfica e visual promover uma formação continuada numa perspectiva humanizadora e sensível, a qual considera a integralidade do sujeito, ou seja, que estimula além do intelecto outras dimensões humanas, como a sensorial, emocional e afetivo. Nessa perspectiva, Gonçalves (2020) destaca que a formação como perspectiva humanizadora viabiliza uma formação abrangente, acolhedora e com ações que promovem a sensibilização dos docentes frente ao cotidiano, portanto considerando uma formação que busca também o desenvolvimento profissional e pessoal. Tais ações formativas foram delineadas, porém contando com as especificidades de cada linguagem no processo formativo.

O empenho em possibilitar a vivência de experiências estéticas permeada pelas diferentes linguagens também vislumbrou a ampliação do repertório cultural da própria professora coordenadora. Nessa perspectiva de formação continuada com a intenção de repertoriar os envolvidos, Nogueira (2010) entende que é um processo em que o sujeito se conecta 
com o mundo da cultura, mundo esse compreendido como um espaço de diferentes leituras do vivido, concretizado nas artes (música, literatura, teatro, dança, artes visuais, cinema, entre outros), portanto, o contato com tais linguagens possibilita a vivências de experiências estéticas significativas.

No movimento de buscar ampliar o repertório cultural dos professores, a própria professora coordenadora percebeu que ela entrou por caminhos que the foram oferecendo vivenciar e experimentar o contato com diferentes linguagens, promovendo assim a vivência de experiências estéticas. Isto foi possível ao mergulhar no propósito de articular as diferentes linguagens no processo formativo proposto para as HTPCs. A seguir delineamos algumas das propostas instituídos nesse contexto formativo.

O prazer pela leitura sempre foi vivenciado pela professora coordenadora, porém ao se debruçar em leituras de diferentes autores da literatura brasileira, fascinou-se com as obras dos autores Carlos Drummond de Andrade, Cecília Meirelles, Vinícius de Moraes, entre outros escritores, passando a selecionar obras desses escritores para as pautas das reuniões de HTPCs. Iniciou assim, a prática de trazer para a HTPC a leitura deleite, ou seja, leitura destinada ao prazer e reflexão do que é lido. Portanto, o movimento realizado por essa ação formativa, conduziu a professora coordenadora a sentimentos e emoções despertados frente a cada obra literária apreciada, conforme Duarte Jr.:

[...] o que ocorre numa experiência estética é que nossos sentimentos são tocados, são despertados pelas formas do objeto e então vibram, dando-se a conhecer a nós mesmo. Como frente a um espelho, onde apreendemos nossa imagem e desvendamos a aparência de nosso corpo, face ao objeto estético descobrimos aspectos de nossa vida interior, vindo a conhecer melhor os nossos sentimentos. Ao revelar-nos o mundo - por meio de seu próprio mundo - o artista nos mostra a nós mesmos. (DUARTE Jr., 2009, p. 52-53).

Dessa forma, buscando tecer experiências de formação acerca da linguagem literária, alargando o repertório literário de todos os envolvidos, a professora coordenadora inseriu os poemas na leitura deleite nas pautas das HTPCs promovendo o prazer da leitura, conforme consta relato em seu diário de bordo:

Meu propósito com as poesias inicialmente era de apenas expandir o repertório poético dos professores, mas como eles as relacionavam ao cotidiano eu deixava fluir as observações e quando pertinente me colocava (Diário de bordo PC, 21/05/2018).

Também foram inseridas crônicas e narrativas docentes, as quais inevitavelmente tocaram os professores, suscitando o exercício de reflexão sobre a própria prática, por meio de diálogos mais livre de escudos, desnudados, pois esse movimento tocou os participantes, instigando-os a tecerem narrativas da própria história de vida pessoal e profissional, ressignificando o exercício da docência. Trazemos a memória registrada pela professora Denise $^{2}$ para exemplificar essa perspectiva:

Ao iniciar nosso encontro, a prof. Coord. Rosy nos passou uma apresentação

2 O projeto foi aprovado pelo Comitê de Ética - Parecer: 2.606.585. Os nomes dos professores são fictícios. 
na qual retomou o texto Teachers of the world, intitulado "Eu me lembro de pensar: a educação aconteceu aqui" (Juliana Gentil) pontuando a questão sobre a formação universitária, vivências diferenciadas em contexto público e privado, até mesmo de outro país; porém o ponto alto do texto e que nos levou a refletir muito é a necessidade de se reinventar a todo momento na carreira escolar, trazendo aos alunos desafios e possibilidades diversas para uma melhoria no processo de ensino aprendizagem (Memórias das HTPCs prof ${ }^{a}$ Denise, 25/04/2018).

A literatura envolvida em narrativas e crônicas, conduziram a reflexões sobre assuntos acerca do cotidiano vivido, além da possibilidade de olhar para nossas experiências. A linguagem literária trouxe à tona a criatividade, a imaginação, a sensibilidade, o resgate de memórias, a criticidade dos professores em um momento acolhedor e propício ao diálogo, conforme seguem relatos:

Neste dia, a abertura de nosso HTPC foi com a canção do Exílio de Gonçalves Dias, a qual trouxe à tona memórias de nossos colegas. Estela que ouvia seu pai cantarolando durante seus afazeres e o Prof. Fernando que decorava para declamar em festividades na escola (Memórias das HTPCs prof ${ }^{a}$ Filomena, $16 / 05 / 2018)$.

A coordenadora iniciou o horário de trabalho pedagógico coletivo (HTPC) com a apresentação de uma crônica da autora Eliane Brum, seguidamente realizou a leitura da mesma. Durante a leitura os professores seguiam atentamente junto ao texto impresso o que estavam ouvindo, o silêncio pairava, algumas risadas foram apresentadas em alguns trechos, mas logo após os lampejos de ruídos, o silêncio tomou conta dos olhos atentos dos professores novamente. Ao término da leitura algumas falas foram sendo pautadas, [...] todos pareciam bem à vontade nas suas falas, criando um ambiente agradável na sala dos professores, fazendo contrapontos nas argumentações e propiciando debates sobre o assunto abordado no texto (Memórias das HTPCs prof. Fernando, 19/09/2018).

Entendemos que esse movimento de contemplar a linguagem literária permitiu quebrar com um olhar naturalizado para com o cotidiano escolar, permitiu quebrar com a "vista cansada" (RESENDE, 1992) aquela vista que não enxerga para além do que está posto. Como salienta Ostetto (2012, p. 22): "Sem nos darmos conta, é assim que inúmeras vezes olhamos para o cotidiano: através de um olhar paralisado, que se gastou, domesticado por uma prática rotineira, enraizada no hábito, que monotonamente se repete, repete, repete".

$\mathrm{O}$ contato com a linguagem literária reflete nossas experiências de vida, pois ela nos traz recordações, denuncia alguns medos e anseios que dificilmente compartilhamos com alguém. Colabora no entendimento de nós mesmos, dos outros e do mundo, pois ela pode ser compreendida como meio para a humanização, transformação, libertação, prazer, alegria e imaginação. Nessa perspectiva, é impossível viver uma experiência estética com a poesia sem a apreciação do sensível. De acordo com Neitzel e Duarte (2006):

Não podemos ler uma poesia, um conto, uma crônica, um romance como quem lê uma bula de remédio ou uma notícia de jornal, pois a literatura desde o sé- 
culo XVIII vem se firmando como fenômeno estético. Evidentemente que a leitura de textos literários nos leva a compreender o mundo, nossos pares que nos rodeiam, a nós próprios, nos alça à compreensão de diversas culturas, nos possibilita a formação de conceitos e à ampliação e aprimoramento de nosso potencial linguístico [...] (NEITZEL; DUARTE, 2006, p. 2).

A inserção da linguagem literária foi um meio lançado para transitar por assuntos mais delicados que, somente com os referenciais teóricos não era possível acessar reflexões sobre a própria ação docente, mergulhar no próprio fazer. Assim, a experiência estética provocada pela literatura rompeu alguns estigmas e crenças acerca do exercício profissional, favorecendo uma maior exposição dos docentes nos momentos de formação.

Dessa forma, compreendemos que a proposição das experiências estéticas disparada pela literatura suscitara diálogos mais abertos, possibilitou que os professores verbalizassem suas ideias, angústias e alegrias de forma espontânea e consciente, compartilhada com seus pares, num espaço formativo que proporcionou o encontro com o outro, aguçando os sentidos e assim instigando a um diálogo mais aberto e carregado de sentido para os participantes.

A constante busca por uma formação continuada dialógica levou a professora coordenadora a promover proposições inspiradoras e permeadas pelas experiências estéticas. Tais proposições objetivavam enxergar as contradições do cotidiano escolar e debatê-las, acolhendo a pluralidade de perspectivas dos docentes de maneira acolhedora. Mas de que forma suscitar o diálogo e o posicionamento crítico dos envolvidos no processo formativo?

Dessa forma, as proposições acerca da linguagem cinematográfica (envolvendo filmes de curta e longa metragem), foram lançadas como mais uma prática formativa que se distanciava de momentos mais formais e centrados na ação da professora coordenadora. A inserção dos filmes não vislumbrava instrumentalizá-los, porém contava com sua potente fonte disparadora de diálogo, onde as subjetividades poderiam ser expostas.

As proposições envolvendo os filmes de curta e longa metragem propostos como disparadores para o diálogo sobre temas importantes e delicados inerentes às práticas, não afastou as possibilidades de sensibilização no momento formativo, pois a professora coordenadora pode no processo de seleção dessas obras, ao contemplá-las vivenciar experiências estéticas, pois se encantou com as imagens, sons, movimentos, cenas e enredo contidos nas produções, ainda que com um olhar desprovido de conhecimento técnico sobre cinema, mas aberta às formas de como elas a afetaram. Dessa maneira, ocorriam as primeiras experiências estéticas desse processo formativo no contato com as obras cinematográficas: "A ponte", produzido por Ting Chian Tey, (2010), "A casa dos pequenos cubinhos" de Kunio Katō, (2008), "Validattion" dirigido por Kurt Kuenne, (2007) e o longa metragem "Extraordinário", obra de Palacio, (2017). Algumas dessas obras foram apresentadas pela professora coordenadora e compartilhadas com os docentes, levando-os a um debate franco e articulado às questões do cotidiano.

Chaluh (2012) ao tratar da proposta dos filmes na formação docente afirma que "Essa experiência promove e potencializa diferentes formas de ler, sendo que tanto a leitura estética quanto a leitura didática possibilitam o tecido de redes de sentidos, sensações, compreensões, reflexões e, juntas, permitem ampliar a leitura e interpretação sobre uma problemática" (CHALUH, 2012, p. 138). 
Nesse processo formativo, os filmes se tornaram fios condutores que geraram debates e discussões, possibilitando articular os enredos às experiências cotidianas, mas, destacamos aqui a maneira como os professores foram afetados pelos filmes. Importa destacar que nas HTPCs nos quais a proposta era a socialização de um filme, o movimento de imersão na obra escolhida era iniciado pela própria professora coordenadora, ao verbalizar suas perspectivas e emoções, rompendo com o silêncio que muitas vezes imperava e buscando inspirar e encorajar os professores a se colocarem, se posicionarem, ou seja, incentivando a troca de olhares e perspectivas frente a cada obra. Conforme, segue o relato:

O curta A Casa dos pequenos cubinhos suscitou inicialmente no grupo de pro-
fessores o sentimento de melancolia, saudades, se assim podemos dizer. No
entanto, fizeram a reflexão acerca da vivência do personagem que foi se adap-
tando a cada etapa de sua vida, como também reflexões sobre as memórias e a
importância da contribuição da mesma na constituição do professor. Busquei
refletir com os grupos de professores sobre o quanto as nossas memórias con-
tribuem para pensarmos o trajeto que nos levou até aqui, o quanto os erros e
acertos contribuíram para a nossa constituição de professor. (Diário de bordo
da P.C, 05/04/2018).

Azevedo; Grammont e Teixeira (2014) apontam que o cinema interpela nosso olhar e as imagens nele contidas provocam deslocamentos e favorece as diferentes formas de ler o filme, contrapondo a nossa compreensão e interpretação do mundo. Esse movimento "ajuda a olhar" o nosso entorno com outras perspectivas, além daquelas que já trazemos por nossa formação histórica.

Nessa perspectiva, os filmes como obra artística dinâmica e expressiva viabilizou as conversas e os diálogos no processo formativo, à medida que as experiências estéticas vividas pelos professores e a professora coordenadora, causaram emoção. Conforme Soto e Vasta (2016, p. 40): "Si tenemos que sintetizar cuáles son las características que hacen a una experiencia estética, podríamos afirmar que en ella los sujetos que participan se conmueven sensiblemente y se detienen en un tiempo que rompe con lo cotidiano".

A proposição com os filmes gradualmente modificou a postura dos professores, pois era perceptível a espontaneidade no posicionamento de cada um, característica igualmente observada nas HTPCs em que envolveram a literatura e narrativas docentes, como já relatado anteriormente. Assim, destacamos mais uma vez a potencialidade das experiências estéticas nessa prática formativa. A escrita da professora coordenadora em seu Diário de bordo transparece de maneira clara tais perspectivas, conforme segue:

Enfim, terminei essa HTPC com a impressão de que o uso de filmes e outras linguagens estimulam os professores a refletirem sobre as temáticas e os encoraja a se posicionarem espontaneamente (Diário de bordo P.C 20/09/2018).

A experiência estética provocada pela linguagem cinematográfica viabilizou a interlocução no processo formativo na escola, ativando os sentidos e abarcando os sentimentos. Santos (2003) afirma que tudo que nos chega a tocar, passa pelos sentidos, estes sensivelmente constituídos, sendo assim estético também. Portanto, as experiências estéticas poten- 
cializadas pelos filmes, impactaram os envolvidos, professores e equipe gestora, justamente por desacomodar os olhares frente às obras vistas, articulando o conteúdo do filme com a realidade vivida. A linguagem cinematográfica ensinou a olhar para nossa rotina e para o outro com olhar mais sensível, ampliado e acolhedor das relações cotidianas. Observamos no relato da professora Kátia um olhar mais sensível para refletir sobre o vivido:

\begin{abstract}
Iniciamos nossa reunião de HTPC assistindo a um curta-metragem "Validation". Após esse curta, fizemos reflexões sobre o mesmo, buscando associá-lo aos pareceres descritivos, visto que estamos no momento de escrita e avaliação do semestre. Nos relatos das professoras identificamos a importância de descrever as qualidades das crianças, pois incentivos, elogios e motivação contribuem para elevar a autoestima das crianças. Também foram relatadas algumas observações de crianças que demonstram dificuldades em sorrir e expressar seus sentimentos [...] (Memórias das HTPCs, prof Kátia, 17/07/2018).
\end{abstract}

Envolvida no processo de formação continuada na escola que fizesse sentido a todos os envolvidos, impulsionando a participação dos professores numa postura crítica, a professora coordenadora encontrou na linguagem visual possibilidades de vivência de experiências estéticas inspiradoras e significativas. Esse fazer formativo, já desvinculado de ações que atrelassem somente os estudos teóricos na formação continuada, permitiu o mergulho na desafiadora prática da leitura de obras de arte, além de proporcionar a vivência de um fazer artístico singular tanto para a professora coordenadora e para os professores.

Inicialmente, as proposições realizadas nas HTPCs envolveram as leituras de obras de arte, propondo que a aproximação inicial deveria ser desprendida de uma leitura técnica das obras, compreendendo apenas uma leitura fruitiva, possibilitando o despertar dos sentidos com essa experiência. Conforme, Momoli e Egas (2015):

A experiência estética, produzida a partir da apreciação da imagem e da obra de arte, permite um modo de compreendermo-nos, confronta-nos com nós mesmos e desvela algo. Aproximar a arte da formação de professores é perseguir a experiência estética como uma mola propulsora dos processos formativos para a docência (MOMOLI; EGAS, 2015, p. 72).

Dessa forma, foi realizada a leitura imagética, cuja característica foi a ênfase no aspecto visual, valendo-se de um conjunto de imagens de obras de arte, sendo elas: O Viajante de Caspar David Friedrich (1993), O Grito de Edvard Munch (1818), O Remo de Wassily Kandinsky (1907), O Beijo de Gustav Klimt (1912). Tal proposição colaborou para ampliar a percepção dos docentes de que a leitura está presente em outros meios que não somente daquelas que empregam textos verbais. Conforme salienta Perissé (2009) "Ler uma obra de arte consiste em criar com ela, a partir dela e além dela: desdobramentos do encontro. Criar com a obra é entrar em sintonia com ela, admirá-la, adjetivá-la, valorá-la e valorizá-la, aderir à sua presença" (PERISSÉ, 2009, p. 42).

Por não ter a titulação em arte, a professora coordenadora realizou as leituras das obras de maneira despretensiosa, não se configurando leituras formais ou técnicas, mas com algumas mediações, intencionava estimular o posicionamento dos docentes quanto a 
maneira que as obras afetaram cada um deles. A intenção dessa leitura consistiu em provocar experiências estéticas capazes de despertar, nos espaços formativos, sentimentos e sensações como: anseios, tristezas, felicidade, saudade, aconchego, inquietações e alento através da Arte, assim como Perissé (2009) ressalta ao explicitar sua potencialidade.

Esse despertar de sentimento através da linguagem visual permitiu aprofundar nas HTPCs o exercício do olhar e da escuta, buscando refletir sobre assuntos do cotidiano que requerem atenção ao outro e às vivências. Segundo Ostetto (2013):

Sensibilizar o movimento, o olhar e a escuta do professor contribuirá, sobretudo, para torná-lo um sujeito mais aberto e plural, mais atento ao outro; ampliará seu repertório e, consequentemente, seu acervo para criação-uma vez que só se cria a partir da combinação de elementos diversos que se tenha-, tornando sua prática mais significativa, autoral e criativa (OSTETTO, 2013, p. 23).

As considerações de Ostetto (2012) contribuíram para que a professora coordenadora pudesse ampliar a reflexão acerca das questões da sensibilidade, compreendendo que enquanto sujeitos podemos (ou não) ser tocados através da arte e os sentimentos que ela pode despertar:

\begin{abstract}
Quando reclamamos a contribuição da arte à formação do professor, temos em mente que ela congrega um conhecimento que trabalha com as polaridades: ao possibilitar o gostoso, também engendra o desgostoso; ao dar prazer, também provoca desprazer; se traz satisfação, igualmente dá frustração; se permite trazer à tona a luz da existência, também mexe com as sombras do ser humano; o sublime e o horrível, o belo e o feio: está tudo aí, no processo artístico. Na arte, em suas diferentes linguagens, não emerge apenas a fada, mas a bruxa, os ódios, o fundo do baú da nossa vida. Por isso, arte mexe com a totalidade (OSTETTO, 2012, p. 12).
\end{abstract}

A contemplação das obras de arte no contexto das HTPCs foram possibilitadoras de inúmeras experiências estéticas. $\mathrm{O}$ encontro dos participantes com as obras refletiu em múltiplos sentidos e entendimentos. Destacamos que a contemplação da obra em si, já se constitui em momento prazeroso, sendo potencialmente pertinente ao diálogo, ao posicionamento crítico e consequentemente ao caminho de uma formação humanizadora, qual estimula a percepção de si, do outro e ao o que nos cerca. Nogueira (2010) nos ajuda a compreender a importância das obras de arte e sua relevância na nossa formação:

Diferentemente as obras de arte, sejam de origem popular ou erudita, promovem no apreciador, seja ele ouvinte ou espectador, um crescimento na direção de sua própria humanização. A relevância da experiência estética está justamente nesse processo, pois é no contato com a Arte, seja assistindo a um filme e sentindo empatia pelos personagens, seja participando de um concerto e se transportando para outro período histórico, seja apreciando uma pintura e vivenciando o ideal de beleza e humanidade nela expresso, o homem anseia por absorver o mundo e, ao mesmo tempo, integrá-lo a si mesmo (NOGUEIRA, 2010, p. 11). 
Sucederam às leituras de obras outro momento formativo inspirador e convidativo à possibilidade de vivências de experiências estéticas a partir da realização de uma oficina artística.

\section{OFICINA: DA EXPERIMENTAÇÃO DE MATERIAIS À CRIAÇÃO ARTÍSTICA}

É necessário que sejam apresentadas diversas outras possibilidades e formas de aproximar os professores de experiências estéticas, desmistificando o fazer artístico como um dom e a desconstrução dos estereótipos que são cristalizados nas linguagens artísticas. Tal movimento formativo, em que as linguagens permeiam as proposições, estimula a percepção do professor para que também se expresse artisticamente em seu fazer pedagógico.

Dessa forma, a proposição da oficina artística, coordenada pelo professor de Arte João junto com a professora coordenadora, conduziu a experimentação de materiais, entre elas a tinta guache, pincel, telas, tecidos. Especificamente a pintura, permitiu aflorar os sentidos e percepções, como ao observar as cores, cheiro e a textura da tinta, deixando fruir a criatividade e a sensibilidade expressada nas criações de cada participante.

Esse momento de partilha, ao vivenciar a experiência de pintar, favoreceu a troca de diferentes olhares dos professores referentes ao processo de experimentar materiais e criar produções artísticas, assim, Ostetto (2013) corrobora com a importância de também ampliar o repertório dos docentes, através de abordagem que os aproxime da pluralidade cultural e os coloque em momentos de autoria:

Nesse sentido, a avaliação da professora Sandra referente às formações em HTPC do ano letivo de 2018, nos revela que é possível e indicado ter espaços para as experiências estéticas nos momentos de formação continuada na escola, mesmo que seja um processo gradual e tímido.

\footnotetext{
Não vejo necessidade de mudanças, uma vez que foram todas muito bem estruturadas. Porém, a HTPC da oficina de Arte foi um arraso! Acredito que todos sentiram-se muito bem. Minha sugestão seria ter uma HTPC nesse estilo a cada trimestre. Tivemos uma de Arte, as próximas poderiam ser de música, danças circulares etc. (Avaliação das formações em HTPC 2018, prof ${ }^{a}$ Sandra).
}

Portanto, a avaliação da professora Sandra apresenta indícios de que tal proposição desafiou as vivências estéticas propostas no processo de formação continuada realizados na escola. Esse momento de inspiração e expressão de sentimentos e sensações indica a necessidade de estimular outras dimensões para a formação continuada que contemple uma formação humanizadora e sensível.

A seguir, algumas imagens da formação ocorrida em HTPC com a proposição da oficina artística: 


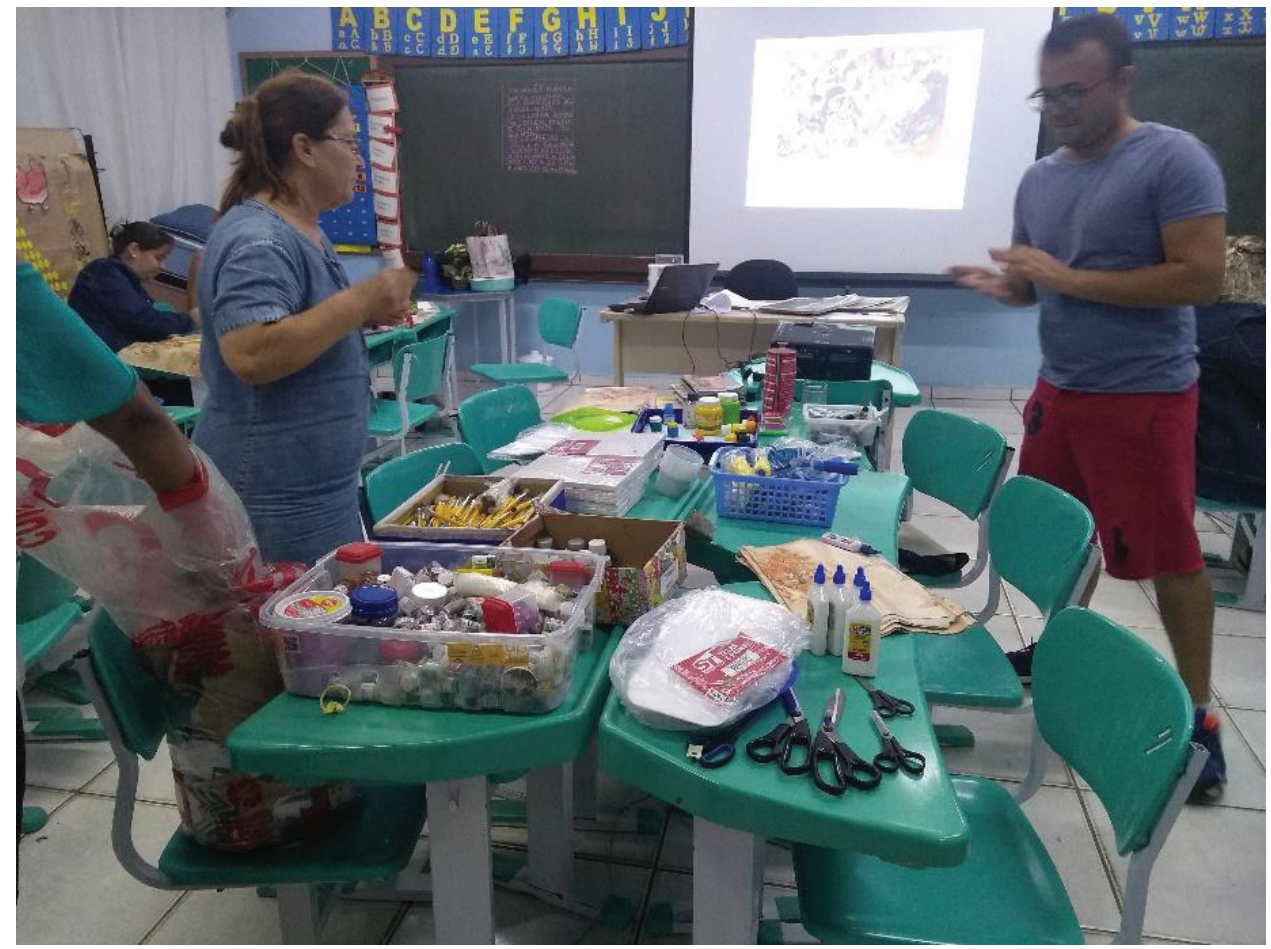

Figura 1: Escolha de materiais

Fonte: GONÇALVES, 2018

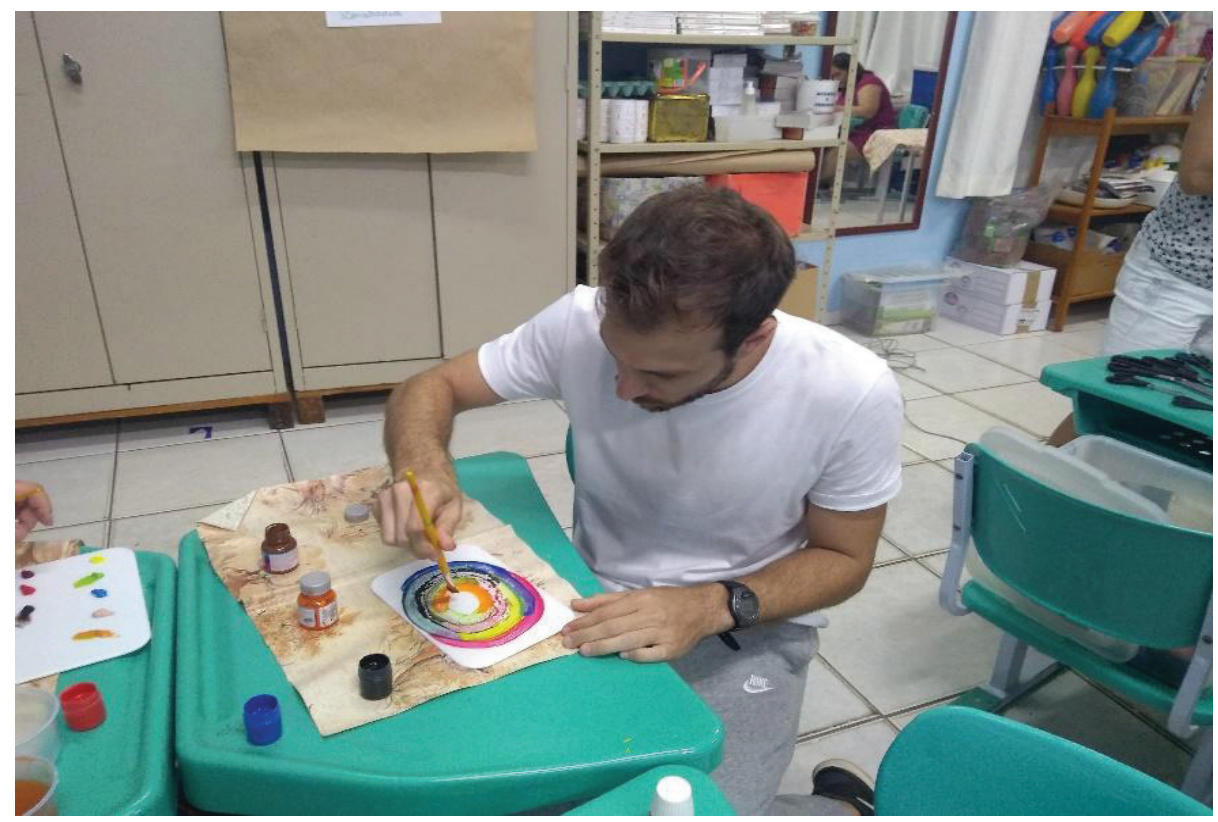

Figura 2: Pintura em tela de isopor

Fonte: GONÇALVES, 201 


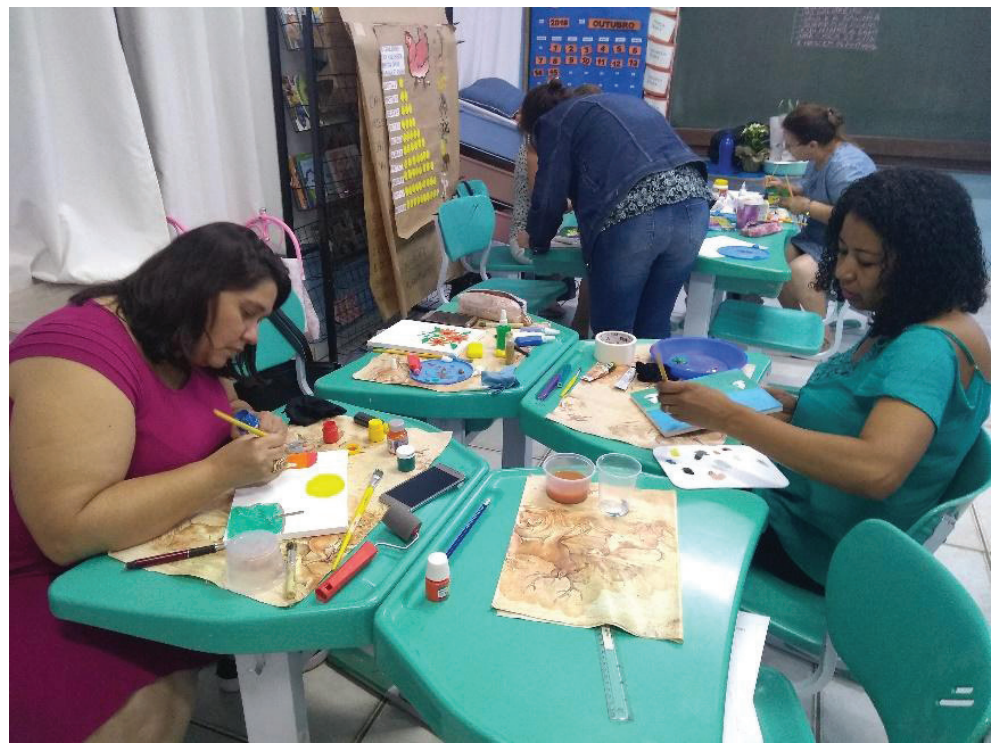

Figura 3: pintura em tela

Fonte: GONÇALVES, 2018.

\section{Algumas lições da eXPeriênCIa VIVIDA}

Este artigo socializou um recorte de uma pesquisa narrativa que apresentou uma proposta outra de formação continuada, que tinha a intencionalidade de provocar o processo de reflexão nos professores, sabendo que isto poderia ter implicações na prática docente. Porém, não era objeto da pesquisa analisar tais implicações, mas sim compreender os movimentos formativos permeados pelas experiências estéticas entrelaçadas às linguagens literárias, cinematográficas e visuais. E esse modo de fazer pesquisa, pesquisa narrativa, ao considerar como objeto de estudo as próprias práticas formativas instituídas pela professora coordenadora, deixou em evidência que a experiência estética se tornou um meio para questionar a formação continuada na escola, o que implicou a ressignificação da própria atuação da professora coordenadora naquele contexto, resultando em lições significativas que a conduziram na tomada de consciência de seu próprio processo formativo e na percepção das implicações enquanto formadora.

Segundo Lima, Geraldi e Geraldi (2015), a especificidade da pesquisa narrativa reside no fato de que:

[...] o sujeito da experiência a narra para, debruçando-se sobre o seu próprio vivido e narrado, extrair lições que valham como conhecimentos produzidos $a$ posteriori, resultando do embate entre a experiência e os estudos teóricos realizados após a experiência narrada. [...] É da experiência vivida que emergem temas e perguntas a partir dos quais se elegem os referenciais teóricos com os quais se irá dialogar e que, por sua vez, fazem emergir as lições a serem tiradas (LIMA; GERALDI; GERALDI, 2015, p. 26-27). 
Com isto, a concepção de pesquisa narrativa que neste trabalho se apresenta está relacionada à ideia de narrativa benjaminiana. Segundo Benjamin (1994) as lições (ou conselhos) extraídas das narrativas orais não guardavam relação com a ideia de deixar uma moral, ao contrário elas afirmavam a necessidade de dar continuidade ao que foi narrado, Isto porque "Aconselhar é menos responder a uma pergunta que fazer uma sugestão sobre a continuação de uma história que está sendo narrada" (BENJAMIN, 1994, p. 200). Como continua a história?

Assim, neste tópico trazemos as lições/conselhos que surgiram a partir do movimento de mergulhar na experiência vivida pela professora coordenadora e, que no diálogo com os diferentes teóricos, permitiu ampliar o olhar e colocar num outro patamar o vivido para ampliar os sentidos. Lições/conselhos que no encontro com novos professores coordenadores vão ganhar novos sentidos porque segundo Benjamin, a narrativa "[...] não se entrega. Ela conserva suas forças e depois de muito tempo ainda é capaz de se desenvolver" (BENJAMIN, 1994, p. 204).

A professora coordenadora se preocupou em alargar a maneira como ela e os docentes enxergavam a realidade, viabilizando esse exercício constantemente. E para a realização desse movimento, proposições significativas e provocativas foram lançadas no meio formativo promovendo o encontro e o entrelaçamento das linguagens nas formações, delineando proposições que ampliasse os olhares, as escutas e os movimentos sensíveis, capazes de despertar linguagens adormecidas (LEITE; OSTETTO, 2012).

Esse movimento inquieto de buscar pelas linguagens como meio formativo inspirador, possibilitou a professora coordenadora a reconhecer a necessidade de aprender mais, de conhecer mais, passando a questionar seu próprio repertório cultural, concluindo que havia necessidade de nutrir-se, ou seja, de beber das fontes da literatura, da linguagem visual e da linguagem cinematográfica, justamente para potencializar os processos formativos que almejava. Portanto, a professora coordenadora encontrou nas diferentes linguagens um meio para adentrar nas discussões e trazer ao centro das formações as diferentes temáticas de estudos de forma que as perspectivas, pensamentos e sentimentos dos professores fossem postas e a singularidade de cada um fosse considerada e externada no grupo. Assim, a professora coordenadora se colocou como mediadora desse processo para ampliar o horizonte: "para ampliar o olhar, a percepção, o sentir e o pensar sobre a educação e para promover a ação" (CHALUH, 2012, p. 135) dos professores inseridos no processo formativo.

Segundo Soto e Vasta (2016),

La experiencia estética que cada individuo transite en el correr de sus días estará mediada por sus circunstancias de vida y enraizada con ella, pero creemos necesario explicitar que la educación estética producirá en cada individuo posibilidades diversas. Su bagaje de experiencias estéticas será el motor de los nuevos aprendizajes y ampliará sus posibilidades de contactarse con hechos que estaban allí y que a veces no percibía (SOTO; VASTA, 2016, p. 36).

Após mergulhar no processo formativo na escola permeado pelas linguagens que favoreceram reflexões múltiplas, além de vivências de experiências estéticas da professora coordenadora e dos professores envolvidos, ela já não se reconhece com o mesmo perfil de professora coordenadora, pois desconstruiu concepções e ideias sobre uma formação continuada realizada somente com viés teórico. 
Portanto, a professora coordenadora apropriou-se do conceito experiência estética de forma ampla, ou seja, não somente pelo viés do sensível, mas compreendendo sua definição e indefinição, a partir de diferentes contextos. No entanto, evidencia a compreensão de que a experiência estética, permeada pelas diferentes linguagens, na formação continuada de professor pode ser um caminho para sensibilizar e desnaturalizar seu olhar cristalizado do cotidiano e, no seu lugar, se atentar a um olhar humano que enxergue as contradições vividas nas relações e nos processos formativos.

Finalmente enfatizamos algumas questões que já foram explicitadas anteriormente, porém que merecem um destaque para legitimar sua importância. Primeira questão: resgatar as histórias de vida, a dimensão pessoal e profissional dos docentes com os quais se compartilha a vida escolar abrindo espaço para que as memórias circulem e, com elas, todos os sujeitos envolvidos e suas próprias experiências. Segunda questão: se expor para os outros, mostrar o que se pensa/sente, isto implica a construção de um contexto que ofereça confiança e segurança. E na roda, no entrelaçamento das histórias problematizar e contrapor pontos de vista, pensamentos, concepções o que possibilita quebrar com ideias arraigadas e com um olhar naturalizado/banalizado que não permite avançar nas compreensões. Terceira questão: assumir uma concepção de formação atenta à sensibilidade e experiências estéticas não requer uma formação no contexto de especialização em estética/arte, mas compreender que o encontro do sensível entre este mundo que pode embaçar o olhar e a leitura pessoal que cada sujeito faz acerca do mundo, pode construir um olhar sensível e acolhedor das singularidades.

\section{REFERÊNCIAS}

AZEVEDO, A. L. F.; GRAMMONT, M. J.; TEIXEIRA, I. A. C. "Me ajuda a olhar": o cinema na formação de professores(as). Educação em Foco, v. 17, n. 24, p. 123-143, 2014.

BAKHTIN, M. Marxismo e filosofia da linguagem. São Paulo: Hucitec, 1999.

BENJAMIN, W. Magia e técnica, arte e política: ensaios sobre literatura e história da cultura. 7 ed. São Paulo: Brasiliense, 1994.

CATANI, D. B. A autobiografia como saber e a educação como invenção de si. In: SOUZA, E. C. de; ABRAHÃO, M. H. M. B., (Orgs.). Tempos, narrativas e ficções: a invenção de si. Porto Alegre: EDIPUCRS, 2006.

CHALUH, L. N. Filmes na formação de futuros professores: educar o olhar. Educação em Revista, Belo Horizonte, v. 28, n. 2, p. 133-152, jun. 2012.

CHALUH, L. N. Formação e alteridade: pesquisa na e com a escola. 2008. 290 f. Tese (Doutorado em Educação) - Faculdade de Educação, Universidade Estadual de Campinas, Campinas, 2008. 
DUARTE, F. Jr. O que é beleza? 3. ed. São Paulo: Brasiliense, 1991.

FREIRE, M. Educador, educa a dor. São Paulo: Paz e Terra, 1987.

FREIRE, P. Pedagogia da autonomia: saberes necessários à prática educativa. 25. ed. Rio de Janeiro: Paz e Terra, 1996.

FRIEDRICH, C. D. O Viajante Sobre o Mar de Névoa. 1818. Disponível em: https:// www.jornaltornado.pt/o-viajante-sobre-o-mar-de-nevoa-caspar-david-friedrich/. Acesso em: 19 dez. 2018.

GADAMER, H. G. Hermenêutica da obra de arte. São Paulo: Martins Fontes; 2010.

GONÇALVES, R. Experiências estéticas na formação de professores na escola: mediação da professora coordenadora 2020. 193f. Dissertação (Mestrado em Educação) - Instituto de Biociências, Universidade Estadual Paulista, Rio Claro/SP, 2020.

GINZBURG, C. Sinais: raízes de um paradigma indiciário. In: GINZBURG, C. Mitos, emblemas, sinais. São Paulo: Companhia das Letras, 1989. p.143-179.

KANDINSKY, W. O Remo. 1912. Disponível em: https://pt.artsdot.com/@@/8XZ6Q2-Wassily-Kandinsky-Improvisa\%C3\%A7\%C3\%A3o-26--remo-. Acesso em: 15 jun. 2018.

KLIMT, G. O Beijo. 1907. Disponível em: https://pt.artsdot.com/@@/5ZKCLN-Gustav-Klimt-o-beijo-(-Bacio-). Acesso em: 15 jun. 2018.

LIMA, M. E. C. de C.; GERALDI, C. M. G.; GERALDI, J. W. O trabalho com narrativas na investigação em educação. Educação em Revista, Belo Horizonte, v. 31, n. 1, p. 17-44, jan/mar. 2015.

LEITE, M. I.; OSTETTO, L. E. Formação de professores: o convite da arte. In: OSTETTO, L. E.; LEITE, M. I. Arte, Infância e formação de professores: autoria e transgressão. 7. ed. Campinas, SP: Papirus, 2012. p. 11-24.

LOPONTE. L. G. Tudo isso que chamamos de formação estética: ressonâncias para a docência. Revista Brasileira de Educação. Porto Alegre-RS, v. 22, n. 69, abr.jun. 2017.

MOMOLI, D.; EGAS, O. A dimensão estética na formação dos pedagogos. Trama Interdisciplinar, São Paulo, v. 6, n. 2, p. 59-74, maio/ago. 2015. Disponível em: https:/editorarevistas.mackenzie.br/index.php/tint/article/download/8341/5398. Acesso em 26 set. 2019.

MUNCH, E. O Grito. 1893. Disponível em: https://pt.artsdot.com/@@/8XXU4K-Edvard-Munch-O-Grito. Acesso em: 15 jun. 2018. 
NEITZEL, A. de A.; DUARTE, B.K. da C. Poesia na escola: educação para fruição estética. In $16^{\circ} \mathrm{COLE}-\mathrm{CONGRESSO}$ DE LEITURA DO BRASIL, 16., 2007, Campinas. Resumo dos Cenários: dobras da leitura, 2007. Disponível em: http:www.alb.com.br/anais16/ sem08pdf/sm08ss01_05.pdf. Acesso em: 18 fev.2019.

NOGUEIRA, M. A. Formação cultural de professores. Salto para o futuro. Ano XX, Boletim 7, jun. 2010.

OSTETTO, L. E. Observação, registro, documentação: Nomear e significar as experiências. In: OSTETTO, L. E. (org.). Educação Infantil: saberes e fazeres da formação de professores. Campinas: Papirus, 2012. p. 13-32.

OSTETTO, L. E; LEITE, M. I. Arte, Infância e formação de professores: autoria e transgressão. Campinas: Papirus, 2013.

PERISSÉ. G. Estética e Educação. 2. ed. Belo Horizonte: Autêntica, 2009.

RESENDE, O. L. Vista Cansada. Folha de S. Paulo, edição de 23 de fevereiro de 1992. Disponível em: https://cronicabrasileira.org.br/cronicas/7040/vista-cansada. Acesso em: 15 jul. 2017.

SANTOS. F. A estética Máxima. Argos, 2003.

SILVA, G. M. O. Formação (cultural) docente: a inovação do cinema. In: SILVA, G. M. O. Didática e prática de ensino na relação com a escola. EDUECE-2014.

SOTO, C; VASTA, L. Educación Estética en los primeros años. In: ROSA, V.; SOTO, C. Experiencias estéticas en los primeros años. Reflexiones y propuestas de enseñanza. Buenos Aires, Ediciones Paidós, 2016.

\section{DADOS DAS AUTORAS}

\section{Rosy Gonçalves}

Mestre em Educação pelo Programa de Pós-Graduação em Educação do Instituto de Biociências da Universidade Estadual Paulista (UNESP), Rio Claro/SP. Professora Coordenadora na rede municipal de Rio Claro/SP. rosygoncalvess@gmail.com

\section{Laura Noemi Chaluh}

Docente do Departamento de Educação e do Programa de Pós-Graduação em Educação do Instituto de Biociências da Universidade Estadual Paulista (UNESP), Rio Claro/SP. laura. chaluh@unesp.br

Submetido em: 08-12-2020

Aceito em: 22-08-2021 